This is a self-archived - parallel published version of this article in the publication archive of the University of Vaasa. It might differ from the original.

\title{
SME managers' causal beliefs on HRM as success factor of the firm
}

Author(s): Viitala, Riitta; Vesalainen, Jukka; Uotila, Timo-Pekka

Title: $\quad$ SME managers' causal beliefs on HRM as success factor of the firm

Year: $\quad 2020$

Version: Accepted Manuscript

Copyright (C) Taylor \& Francis, International Council for Small Business. CC BYNC-ND. This is an Accepted Manuscript of an article published by Taylor \& Francis in Journal of Small Business Management on 11.8.2020, available online:

http://www.tandfonline.com/10.1080/o0472778.2020.1758528.

\section{Please cite the original version:}

Viitala, R., Vesalainen, J. \& Uotila, T.-P. (2020). SME managers' causal beliefs on HRM as success factor of the firm. Journal of Small Business Management, https://doi.org/10.108o/o0472778.2020.1758528 


\title{
SME managers' causal beliefs on HRM as success factor of the firm
}

\author{
Riitta Viitala, \\ Department of Management, University of Vaasa \\ Vaasa, Finland, P.O. Box 700, FI-65101 \\ e-mail: rst@uva.fi \\ Tel.: +358294498431 \\ Jukka Vesalainen \\ Department of Management, University of Vaasa \\ Vaasa, Finland, P.O. Box 700, FI-65101 \\ e-mail: jve@uva.fi \\ Tel.: +358505625048 \\ Timo-Pekka Uotila \\ Haaga-Helia, StartUp School \\ Helsinki, Finland, Ratapihantie 13, FI-00520 \\ e-mail: timo-pekka.uotila@ haaga-helia.fi \\ Tel: +358504139427
}

\begin{abstract}
Normative human resource management (HRM) literature offers an abundant and sophisticated picture on the ideal HRM practices leading to certain positive HRM outcomes. Explanatory empirical research has also confirmed positive relationships between HRM and organizational performance. This study approached SMEs HRM from a different perspective. We studied how HRM manifests itself in managerial perceptions concerning the important drivers of firm performance. A research strategy was followed that addressed HRM as it naturally manifests itself within holistic managerial thinking. A causal mapping technique was used to elicit causal maps for 37 CEOs of industrial SMEs. The findings indicate that HRM has a varying role as a
\end{abstract}


performance driver in managers' causal beliefs. As the main result we propose a categorization of SME managers' thinking on HRM consisting of four types with different level of conceptual richness and cognitive complexity: Managers with mature, narrow, scattered and vague causal beliefs of HRM as a driver for organizational performance.

\section{Introduction}

Scholars of human resources management (HRM) recommend that it is important to develop efficient HRM practices to achieve positive HRM outcomes, which, in turn, improve the performance of the firm (e.g. Becker and Gerhart 1996; Guest 1997; 2011; Mitchell, Obeidat, and Bray 2013). Despite their potential, not all firms apply HRM practices widely. Previous studies have shown a considerable diversity in HRM practices particularly among SMEs (Aragon-Sanchez and Sanchez-Marin 2005; Cassell, Nadin, Gray, and Clegg 2002; Psychogios, Szamosi, Prouska, and Brewster 2015). One reason for this has been traced back to top management thinking concerning HRM as a driver of organizational performance (Arthur, Herdman, and Yang 2016). Managing director's role as an HRM decision maker is especially important in SMEs because they rarely employ HRM experts (Kotey and Slade 2005; Marlow, Taylor, and Thompson 2010; Psychogios et al. 2015), and therefore, their beliefs and knowledge of HRM may critically influence the status of HRM in the firm (Cardon and Stevens 2004; Papadakis and Barwise 2002). Regardless of its importance little is known about managerial thinking concerning the importance of HRM as a success driver in general and concerning SMEs in particular. 
While several statistical studies link HRM issues to firm performance (Huselid 1995; Boselie, Dietz, and Boon 2005; Combs, Liu, Hall, and Ketchen 2006; Subramony 2009), we do not yet know how SME managers actually see the connection or how they perceive the important elements of HRM and the dynamics between HRM and firm performance. Those studies addressing managerial thinking are usually comparative surveys focusing mostly on the HRM -related perceptions of managers or HRM experts in larger multinational companies (Allison and Hayes 2000; Markoczy 1995; Sadler-Smith 1998; Budhwar and Sparrow 2002; Arthur et al. 2016). Especially qualitative research on HRM -related managerial thinking is scarce (Busenbark, Krause, Boivie, and Graffin 2016; Markoulli, Lee, Byington, and Felps 2016).

We seek two kinds of theoretical contribution with this research. First, we bring new perspective to research on managerial thinking, which mostly addresses managerial cognitions of firm's external environment (e.g. Barr \& Huff 1997; Reger \& Palmer 1996; Calori, Johnson \& Sarnin 1994; Daniels, Johnson \& Chernatony 1994; Hodgkinson \& Johnson 1994; Porac \& Thomas 1990; Porac, Thomas \& Baden-Fuller 1989; Reger \& Huff 1993). So far, only a limited amount of studies have been made on managers' thinking of internal factors of the firm in relation to firm success (Crilly \& Sloan 2012; Eggers \& Kaplan 2009; Kaplan 2008 Laamanen \& Wallin 2009). Thus we aim to broaden understanding of managerial thinking of internal factors as performance indicators for the firm ('the managerial success formula'), especially those related to HRM. Second, to our knowledge, only the study of Arthur, Herdman and Yang (2016) has so far focused on top manager's thinking on HRM issues in relation to firm performance in SMEs. As a result of their empirical study they suggested managerial beliefs on HRM to be the decisive for making investments in human resources of a firm. They label this "HR cause-effect belief'. However, 
when they explicitly suggested the potential HRM perspectives for managers to be considered, we try to find out, what issues and causalities the managers themselves present without any conceptual directing by the interviewer. We particularly seek their spontaneous cause-and-effect explanations between, HRM practices, HRM outcomes and various success factors of a firm. That is to say, we did not want to spoon-feed HRM issues to our informants, and instead monitored if and how the topic of HRM emerged spontaneously among the manager's overall perceptions of important performance factors for the firm. In such a way, our research offers a complementary and alternative view within the current body of knowledge dominated by normative literature and explanatory research.

In this study we wish to open "the black-box" as it manifests in managers strategic HRM thinking by answering the next research questions 1) What HRM practices and HR outcomes do SME managers perceive to be important elements for performance of a firm? 2) What kind of causalities do SME managers see between HRM practices, HRM outcomes and organizational performance? and 3) Are there differences in managerial thinking concerning HRM and if so what kind of differences can be found?

The empirical data consist of interviews with 37 SME managers in the same industry (mechanical manufacturing industry). The interview data were collected using the laddering technique (Bourne and Jenkins 2005; Eden and Ackermann 1998) and analyzed by combining content analysis and a cognitive mapping technique (Bartunek, Gordon, and Weathersby 1983; Laukkanen 1998). We 
differences made it possible to extract various HRM-related logics and compare SME managers in terms of cognitive complexity based on individual causal beliefs.

\section{Theoretical connections between HRM and the performance of a firm}

HRM is a broad area in management including a lot of HRM practices with many different goals in relation to personnel and human capital of a firm. According to the fundamental idea of strategic HRM, HRM practices (e.g., selection, training, and rewarding) are causally linked to HRM outcomes (e.g., commitment, quality, and flexibility), and further to behavioral outcomes (e.g., effort/motivation, involvement, and organizational citizenship), and to performance outcomes (e.g., innovations, quality, and customer satisfaction) and finally, to financial outcomes (e.g., productivity, profit and return on investment). (Guest 1997). Several comprehensive empirical studies offer evidence of the positive connection between the use of HRM practices and firm performance (Huselid 1995; Guthrie 2001; Evans and Davis 2005; Snape and Redman 2010; Ehrnrooth and Björkman 2012; Jiang, Takeuchi, and Lepak 2013). It has been estimated that 20\% of the difference in performance between organizations can be explained by HRM practices (Combs et al. 2006, p. 517).

According to the extensive literature review of Posthuma, Campion, Masimova, and Campion (2013) the most often cited HRM practices are: compensation and benefits; job and work design; training and development; recruiting and selection; employee relations; communications; performance management and appraisal; promotions; turnover, retention, and exit management (Posthuma et al. 2013). In HRM studies these are often conceptually categorized as "clusters" or "bundles" with slightly varying goals. One of the most relevant categorizations is the model of 
three bundles: 1) empowerment-enhancing bundle, 2) motivation-enhancing bundle, and 3) skillenhancing bundle. It has been well described and tested in the meta-analysis of Combs, Liu, Hall and Ketchen, (2006) and Subramony (2009). Empowerment-enhancing bundle consist of HRM practices aiming to strengthen the agency of employees for example by facilitating employee participation in decision making. HRM practices such as autonomous work-groups, employee participation practices, job enrichment, grievance procedures, as well as initiative and feed-back systems belong to this category, as well. These can be used as means to strengthen autonomy and responsibility, as well as initiative among employees. Motivation-enhancing bundle consists of HRM practices seeking to direct employees to show high level of performance by motivating and directing them to concentrate and improve their efforts on tasks which are important from a firm's perspective. HRM practices such as performance-linked rewarding, performance appraisal procedures, career mobility and planning and health care benefits are included in this bundle. Skillenhancing bundle consists of HRM practices targeting to develop employee capabilities to successfully execute the tasks needed to meet organizational goals. Recruitment and selection procedures, job and requirement descriptions, training and development practices are examples of HRM practices of this bundle. Subramony's (2009) meta-analysis revealed a positive relationship between all the three bundles with various business outcomes. It also supported the fundamental idea of "bundle-theory" that the connection between different bundles and performance is stronger than that between single HRM practices and performance. Interestingly, it also showed that the connection is stronger in manufacturing than in service companies.

Several studies have shown the connection between HRM and firm performance in SMEs (Carlson, Upton, and Seaman 2006; Sels, De Winne, Maes, Delmotte, Faems, and Forrier 2006; 
Messersmith and Guthrie 2010; Razouk 2011; Sheehan 2013). For example, Carlson, et al., (2006) studied 168 SMEs and found five HRM practices (training and development, recruitment package, maintaining morale, use of performance appraisals, and competitive compensation) to be more important in high-performing firms than in low-performing ones. Sels et al. (2006) found that although wider use of HRM practices increased labor costs, it enhanced the profitability of the firm. Furthermore, Sheehan's (2013) longitudinal study of 336 SMEs showed that the use of human resource practices enhanced profitability and innovativeness in firms. The findings also showed a longitudinal connection between HRM and performance in terms of not only achieving better performance but also maintaining it over a five-year observation period. Training and development was most significantly associated with performance indicators. Sometimes the causal mechanism was unexpected, as in Pajo, Goetzer, and Guenole (2010) who found training and development increased employee awareness of organizational support, and also affective commitment and job satisfaction, which again were connected to better performance.

Managing directors play a distinctive role in the strategic decision making in a firm (Arendt et al. 2005; Papadakis \& Barwise, 2002).. Therefore it is understandable that research on managerial cognitions suggest that top managers' cognitive processes related to scanning, sensemaking and interpretation are important factors when trying to understand their actions as decision makers and the strategic choices of a firm accordingly (Hodgkinson \& Sparrow, 2000). The fact is that even if the prior research on the HRM-performance link seems to verify the role of HRM as a driver of firm-level performance, research-based view of top managers' thinking of the topic is very scarce. Already 13 years ago Becker and Huselid (2006) suggested that we should try to understand better the variance in HRM "quality" across firms by investigating the level of HRM knowledge of managers. However, very little has been done so far. Arthur et al. (2016) are the few who have 
approached top management's perceptions on HRM as performance factor. Their empirical study in 204 franchise hotels in the USA revealed that managers' value-based HR cause-effect beliefs significantly affected the adoption of HRM practices in their firms. They measured cause-effect belief by asking respondents (members of top management team) only to rank five performance factors (technology, improvements in the quality of materials, HR programs, physical plant improvements and customer service program) from 1 to 5 based on "the degree to which investments in this area impact hotel performance" (ibid. p. 420). Their findings clearly supported the hypothesis that managers' cause-effect beliefs play a significant role in adopting HRM practices and also influence their efficiency in organizations. Our study is strongly inspired by the study of Arthur et al. (2016). Our approach is, however, different as we apply more clearly the causal mapping procedure explained in more detail in the next section.

\section{Data and Methodology}

Research on managerial thinking can be classified into five separate approaches: managerial attention, categorization, causality, argumentation, and schemas (Huff 2013). The current study addresses managers' causal beliefs on the link between HRM practices, HRM outcomes, and firm performance. Causal beliefs are important means by which individuals can organize the complexity of the world and thus make decisions more easily. Danks, for example, (2009) described humans as causal cognizers, who tend to learn the causal structure of the world, use causal knowledge to make decisions and predictions, and use their beliefs to generate explanations of causalities. We addresses causal beliefs of managers holding a CEO position in an industrial (metal and engineering industries) SME. Common denominators for the interviewed managers 
were the industry and CEO position of manager in a SME. According to previous studies, both the industry and the size of the firm influence the emphasis placed upon HRM policies (Choo, Halim, and Keng-Howe 2010. Restricting contextual differences is recommended as a means of making individual managers' cognitive maps comparable when the individuals share a cultural closeness (Jenkins and Johnson 1997; Eden and Ackermann 1998).

We started gathering theinterviewees by listing suitable firms in five provinces using internetbased regional business directories and companies' homepages. We contacted the managing directors of the firms by telephone and explained the idea of our study and the protocol of the faceto-face interview. In this phase the usual reaction of contacted managers was curious and positive, but some of them refused to participate because of their tight timetables. At the end of the day we found 37 managers, who volunteered as informants in our study.

Several features were common for the informants. All the managers had an engineering education except two with business education. All but two of the interviewees were men, and the age of the group ranged from 37 to 62 years old. All had considerable experience within the industry and had been in their current positions for periods ranging from 1 year to 18 years. We assume the managers interviewed represent typical managers in industrial SMEs in Finland. Our aim was not to make any educational or other personal comparisons between the managers, not to speak about comparisons between the companies they represent. However, in order to understand the context, also some details of their companies are worth noticing. They represented SMEs with 50-250 employees and the annual turnover of the firms varied from EUR 1,500,000 to EUR 20,000,000. All the firms had both domestic and international customers. The performance of the companies differed; during the previous five years the average EBIT \% for the companies varied between - 
$1,5 \%$ to $21,7 \%$; and the growth $\%$ varied between $-37,4 \%$ to $69,3 \%$. The companies' were foundries, machine shops, manufacturers for heavy industry, and other technological competence requiring companies. However, we did not investigate actual performance of the firm in relation to top manager's thinking of HRM as performance factor and thus the above remains only as background information.

The key idea of our study was that we wanted to see how managers relate HRM to firm performance as embedded in the overall set of managerial means to achieve high organizational performance. Therefore, we did not ask anything about HRM or any other specific managerial issue in the interviews; all the content on HRM was produced inductively by the interviewees. The interviews were conducted using the laddering technique (Bourne and Jenkins 2005) starting with the question: "What do you consider the most important performance factors of a firm?" The subsequent questions started the path toward understanding each manager's causal beliefs on firm performance: "What are your main managerial means to achieve the goal?" The process continued using back (what causes it) and forth (what are its effects) questions within those managerial areas the interviewee raised. We consciously avoided suggesting the interviewees consider any HRM (or other) topics and stressed that their responses should not be confined to the context of their current firm, but should address success factors on a general level.

The interviews were conducted face-to-face in the manager's office or in a meeting room of the firm and lasted between one hour and two and a half hours, with the average being 90 minutes long. They were tape-recorded and transcribed verbatim for analysis. The interviews produced 467 pages of material comprising around 180,000 words. The explanations or examples that managers 
gave when justifying their causal beliefs varied in length and style. The next examples illustrate the nature of the material:

I would say that first, you need the right strategy and ability to follow through on that strategy. And the thing that ensures you have the ability to follow through on that strategy is the organizational culture. Organizational culture is the biggest success factor. When I've read how organizational culture is defined, well, I think that it's $100 \%$ true that it is the reason why a company succeeds. (Manager 36)

Yeah, I think it's a basic requirement that people enjoy it and like it in the firm. Like, of course this is all dependent on what attitude people come to work with. (Manager 24)

Visualizing the informant's thinking is important with the chosen method (Eden and Ackermann 1998). We tested the practicality of various tools to present the input visually (post-it notes, a white board, and IT applications) in three pilot interviews before the actual interviews. After piloting and analyzing the pros and cons of the techniques among a group of researchers, we found the simple pen-and-paper technique to be the most relevant technique to gather the data. The interviewer sketched a visual map on paper during the interview, and showed the map to the informant at the end of the interview with a summarizing discussion intended to confirm the interviewer's interpretations. Each of the causal maps was drawn and interpreted more thoroughly afterwards based on the transcribed interview, and was sent to the interviewee to be complemented or confirmed.

The starting point of empirical analysis was a dataset consisting of 37 interviews concerning managers' causal beliefs on factors they regard as important for the high performance of firm (Figure 1). This entire data is not the primary source of information for the current research, but 
we were able to make an overview of what kind of general managerial themes the interviewees raised up and what was the relative position of HRM -related issues in managers' thinking. The analysis was continued by selecting all HRM -related texts in the data, which set of data formed the main source of overall descriptive analysis for the purposes of this study. This overall data was content analyzed by using N'Vivo 10 software in order to find out the appearances of HRM related constructs (practices and outcomes) in the data. This analysis makes it possible to give an answer to the research question 1 (What HRM practices and HR outcomes do SME managers perceive to be important elements for performance of a firm?)

Empirical analysis was continued by the final formation and graphical presentation of all the 37 maps of managerial beliefs on HRM as a performance factor. As pointed out earlier, preliminary maps were already sketched during the interviews. In this final phase we used the interview data to further verify that the maps drawn correspond interviewees' actual opinions and sayings. When doing the closer analysis concerning HRM-performance causalities in managers' thinking, we carefully re-red each of the interview transcripts. We also drew more detailed manager-specific maps on the perceived connections between HRM and firm performance. Following the recommendations by Eden and Ackermann (1998), each researcher in the group participated in the analysis by individually drawing the maps of each manager. The maps used in the later analysis were a result of mutual negotiations and comparisons between the maps, sometimes verified by re-reading the interview texts. That step was followed by the analysis of the general patterns of causal beliefs encompassing HRM practices, outcomes, and firm performance. Following the procedure suggested by Tyler and Gnyawali (2009) and Laukkanen (1998) we developed standardized concepts based on initial idiosyncratic concepts in order to enable a comparison of 
manager-specific cause maps. We paid particular attention to the emergence of core HRM constructs in individual manager's maps to understand the dynamics of managerial thinking. Core constructs are the most central nodes through which other nodes are connected (Eden and Ackerman 1992).

After the above procedure the data was in a case data format consisting of 37 graphical maps of managers' causal beliefs. This data is the primary data in this study and it was used to answer the last two research questions. First, we compiled causal maps into one general map showing the general patterns of SME managers' thinking consisting of (1) the most common HRM practices, (2) the most common HRM outcomes and (3) the most common organizational performance criteria, and the observed links between these nodes. This analysis makes it possible to answer to the second research question (What kind of causalities do SME managers see between HRM practices, HRM outcomes and organizational performance?). The study was continued by a comparative analysis of managerial thinking on HRM. We categorized managers into four groups by using three indicators reflecting their HRM thinking: 1) the amount of all the nodes related to HRM issues (incl. HRM practices, HRM outcomes and performance criteria connected to them), 2) the links/nodes ratio of each map and 3) the centrality of HRM core construct in a causal map The first indicator reflects the abundance of HRM related issues in manager's thinking. The second indicator, again, reflects the cognitive complexity (Bartunek et al. 1983) of managers' HRM thinking, which is a result of manager's ability to link HRM issues together (between practices and outcomes) as well as between HRM issues and various performance criteria. The third indicator reflects the quality of managers' HRM thinking by focusing to the centrality of core HRM construct(s) (Eden and Ackerman 1992). 


\section{Findings}

In the following three sections, we first present an overview of the appearance of HRM practices and HRM outcomes (RQ1), followed by the findings concerning general patterns of managers' causal beliefs about different HRM issues and performance (RQ2), and finally the results of the comparative analysis of SME managers categorizing them in four groups according the abundance and cognitive complexity of their thinking related to HRM issues as firm performance drivers (RQ3).

As a short overview on the basis of the whole data, the interviewed managers considered customer relationships, production and technology, and products and product development most frequently as means to high organizational performance. Compared to other themes human resource management get equal attention with themes like supply chain management and partnerships, organization and process development, and strategy and goal setting. As an overall finding we can say that HRM - related means to high organizational performance are not the most common ones in SME managers' managerial arsenal. However, all managers except one did recognize HRM as a performance driver in a way or another and with varying magnitude.

\section{The Appearance of HRM Practices and Outcomes in Managerial Thinking}

The managerial HRM arsenal varied greatly among the managers: nine of them mentioned 10-17 different practices or outcomes, 16 raised between five and nine, and 11 named fewer than five HRM-related issues. In total, managers mentioned 22 different HRM practices (Table 1). We 
used the categorization presented in Posthuma et al. (2013) to group all the mentioned practices and found two new categories of HRM practices: promoting well-being, health, and safety and resourcing. The HRM-practice category turnover, retention and exit management, identified by Posthuma et al. (2013) was completely absent from the data. As many as 21 managers named at least one practice related to training and development as a mean to improve performance. The most often mentioned specific practice was traditional training (14), whereas work-based learning (7), developmental discussions (5), peer learning (3), and knowledge mapping (2) were mentioned by only a few managers. Job and work design was mentioned by (20) managers referring most often to specification of tasks and roles (9) of employees.

>Insert Table 1 here<

The most commonly mentioned HRM outcome was job satisfaction and motivation as 28 managers mentioned it in one form or in other (see Table 2). More specifically, they talked about work engagement (14), job satisfaction (12) and work motivation (10) as the key outcomes of successful HRM. The category knowledge and skills, as well as the category performance of employees were mentioned by 20 managers. The category commitment of employees was identified in one form or another by 15 managers; dynamics of workforce (referring to the attitudinal and skill-based flexibility of employees) was raised by 12 managers; and organizational culture and climate was mentioned by 11 . Four of the managers viewed employer image as an outcome of HRM as an important performance factor of a firm.

>Insert Table 2 here< 
Patterns of Causal Beliefs between HRM Practices, HRM Outcomes, and Organizational Performance

In order to get an overview of the causalities recognized in the group of 37 managers, we combined the detailed information of causal connections between HRM practices, HR outcomes and organizational performance presented by each manager. The most often mentioned connection linked training and development to knowledge and skills: 19 managers raised it up explicitly in their performance explanations. Eight managers explained that job satisfaction and motivation could be influenced by promoting health and safety and seven of them thought that it can be promoted by means of job and work design. Also seven of managers presented job and work design as a means for fostering performance of employees and five of them thought that it can be done mainly by careful recruitment and selection. All of the other causalities were mentioned by only a few managers.

HRM was seen merely as a source for exploitation rather than exploration as the most usual performance factors were effectivity or productivity type of indicators. Regarding the appearance of exploitative pursuit, it is noteworthy that in our sample of 37 managers, only two suggested innovativeness as a strategically important outcome of HRM. This result may stem from all the interviewed managers working in the industrial context at the time. Here is one example of this kind of reasoning where the manager explains how health and safety activity is connected to efficiency:

We have an initiative scheme, but you know, it didn't give us a single development idea. And then we 
had a competition supposedly for health and safety, like who notices the most health and safety issues. We had 70 a month! There was a huge desire to develop things from a health and safety perspective. No one can say that's a bad goal. So, for example, you do a risk analysis about the most critical events that could occur during welding. So, they notice that, hang on, if we improve this here, it'll actually also improve the efficiency of our work procedures. So, through health and safety, we started getting a lot of good stuff for efficient and functional work processes as well. (M31)

When managers talked about HRM practices and outcomes, they rarely very explicitly spoke about causalities between them and firm-level performance. They might say, for example, that "we do not have any performance-based rewards or bonuses" (M19) but stop short of explaining any influences of the policy. Even if they were asked "why so?" or "what influences that?" the causal chains they presented were often short and superficial, for example: training salesmen on products > (leads to) better sales (M25). More detailed, longer, and more cohesive argumentation chains leading from HRM practices to HRM outcomes and, further, to firm performance were quite rare, but some were discernible: Developmental discussion (leads to) > goal and strategic awareness > (increases) trust in management $>$ leads to better work motivation $>$ (leads to) better efficiency $>$ (leads to) better customer value (M5). The longest HRM -related causal chain included seven links, while the average chain had three links. The most typical causal chain for performance was: training employees > (leads to) better knowledge and skills > (leads to) good performance of the firm. In fact, most of the causalities were presented as common truths that did not need further explanation. The findings indicate certain managers had a poor understanding of both the "toolkit" of HRM and its potential to drive performance.

Further, when we analyzed and compared the individual cause maps more thoroughly, we noted 
that for 14 managers the HRM practice knowledge and skills appeared to be the core HRM construct through which several HRM practices were interpreted as affecting firm performance. As an example of rich HRM thinking, the input of M7 indicated "competent personnel" plays a central role in her causal logic. Her means of improving the knowledge and skills of personnel were systematic knowledge reviews, training, recruiting, and engaging personnel. With regard to training, her causal chain started from a developmental discussion > (leading to) training plan > (making it possible to get) effective training > (resulting in) competent personnel. Generally, the most common HRM practices behind knowledge and skills were training, work-based learning, and recruitment.

The HRM outcome job satisfaction was a core HRM construct in six cause maps. The thinking of M1 exemplifies rich managerial thinking centered around job satisfaction as the core HRM construct: he believed that if teams are empowered, the work environment promotes health and safety, communication is open, the common rules are clear, employees can participate in recruitment processes and industrial relations are managed well, employees are satisfied and that drives firm success. Six managers thought that job satisfaction and motivation could be influenced by promoting well-being, health, and safety, and five of them thought that it could be promoted by means of job and work design. Three thought that training and development, employee participation, communications, and compensation and benefits promote job satisfaction.

We found employee performance (referring to performance in general, development activities, and low levels of sickness absence) to be a core construct only in two managers' thinking. Of those two, M37 thought that innovativeness among employees is the most important factor for firm 
success and it could be promoted by empowering people, by work-based learning designed for multiskilled employees, by encouraging a good organizational climate, and by recruiting people representing different skills and experience from different kinds of businesses. The whole group of managers who mentioned it, suggested that it can be promoted by job and work design (7), recruitment and selection (4) and participating employees (5).

\section{Categorizing Managers with Regard to HRM related thinking}

The analysis resulting in the categorization presented in the Table 3 proceeded as follows: 1) all the nodes and all the links in each of the causal maps were counted, 2) the resulting raw data was standardized, 3) links/nodes ratios were counted, 4) core HRM constructs of each causal map was defined and all the links to and from a construct were counted, 5) the categorization of managers in four groups was conducted by a two phase analysis. In the first phase the cases were grouped according to the first two indicators by taking the indicator average as a cutting point. Cases with above average were marked as (+) and cases below average as (-). Double plusses and minuses refer to an indicator score that deviates over 1 standard deviation from the indicator average. After this fairly mechanistic categorization the HRM core construct of each causal map was studied more thoroughly by checking its centrality (the links to and from it). By setting the limit to 5 links differentiating the more developed HRM thinking form others it was possible to 'correct' the first phase analysis. This last procedure changed the categorization of the cases 1, 6, 8, 17 and 33 . The above analysis procedure resulted in a categorization of managers in four groups: managers with mature, scattered, narrow or vague HRM thinking. 
>Insert Table 3 here<

Managers with mature HRM thinking ( $\mathrm{n}=9$ in this sample) connect several HRM practices and outcomes with firm performance and did it with coherent logic. In other words the HRM arsenal manifested in their performance explanation was rich and they presented clear thinking on the meaning and importance of most HRM issues they mention. As an example, causal map of M27 (Figure 2), who builds his causal understanding of HRM through four core HRM-outcome constructs: high work morale, job well-being, highly motivated people, and good knowledge and skills. A notable characteristic of this particular map is the appearance of job well-being activities and the manager's ability to further elaborate on those activities by highlighting several HRM practices. The core HRM construct of highly motivated people is particularly central in his thinking. In common with many other managers, he also evaluates firm success through efficiency. Managers with well-developed thinking on HRM commonly share the idea that people are the most important factor for firm success and a resource that can be nurtured by systematic HRM. Many of the managers with mature hRM thinking referred to a HRM -related issue at the very beginning of the interview. For example, M27 put it this way: "Yes, it is so...all begins with our staff, which is the backbone of our success."

$>$ Insert Figure 2 here <

Managers with scattered HRM thinking $(\mathrm{n}=8)$ were able to list several HRM -related issues, but 
their causal understanding or ability to connect them into a coherent whole was somewhat lower than managers with mature HRM thinking. Their links/nodes ratios were low and their HRM core construct(s) was typically not as central as in the case of more mature thinking. Manager 35 (Figure 2) shows a good example of scattered HRM thinking. He is able to mention quite a lot of different HRM -related issues, but cannot present thinking, which connects the separate HRM -related thoughts into a coherent one. Any of the HRM issues he mention cannot be regarded as a core construct that brings issues elegantly together. A notable feature in his thinking is also the fact that he does not link HRM issues explicitly to any performance factor, but treat the connections as implicitly linking to 'performance'.

Managers with narrow HRM thinking $(\mathrm{n}=7)$ included only few HRM related issues in their causal maps of firm success. However, these few things form a relatively coherent whole and these managers can make sense about the meaning of those issues. Manager 24 represent a typical narrow approach in his HRM thinking (Figure 2). According to his coherent but narrow logic employee participation and continuous development activities affect positively to personnel job satisfaction, which again has a positive link to work which becomes high in quality and effective. This outcome has a straight impact on firm's profit.

Managers with vague HRM thinking $(\mathrm{n}=13)$ were able to mention only few HRM related issues when discussing firm success drivers. Moreover, they more or less listed things without connecting them meaningfully to each other or to any performance factor of a firm. For many of these managers it was not possible to raise any HRM construct as a core construct because any HRM construct mentioned did not have two or more links (Table 3). Manager 25 (Figure 2) is one 
example of those leaders whose HRM thinking was vague if not completely non-existent. The only HRM -related issue he mentions during the long interview was product training, which he sees as a means for improved sales.

Typically, managers with vague or narrow causal maps highlighted flawless performance, right attitude of employees (referring to hardworking and responsible orientation) or experience as the main HRM -related concepts, and training on the job and participating (in production development) as the HRM practices likely to achieve expected outcomes. They emphasized hardworking, skilled, and punctual (essentially harmless) workers as being an important resource for a firm. Such managers tend to think of HRM as an activity that does something to employees, and not for them.

\section{Discussion}

Managerial decision is usually done with limited information making rationality bounded. In such general circumstances managerial beliefs on the effect of certain alternative choices becomes important. Managers, as humans in general, are causal cognizers (Danks, 2009), who use causal knowledge to make decisions and predictions, and use their beliefs to generate alternative choices for successful management. From that point of view, research on managerial causal beliefs offers an excellent viewpoint to enlarge theoretical understanding of the behavior of the firm. In this study, we have focused on industrial SME managers' causal beliefs on HRM as an organizational performance driver. By the chosen research theme and with the inductive research approach we 
are able to contribute to the theoretical understanding of SME management, particularly concerning the role of HRM. As we have shown, there seems to be a clear gap in knowledge concerning both SME managers' thinking in general and their HRM -related thinking in particular. With this study we broadened understanding of managerial thinking concerning internal factors for performance of the firm (called 'managerial success formula'), especially those related to HRM. Our study complements existing knowledge of SME managers' HRM perceptions, which has rarely approached so far. Below, we discuss in more detail the theoretical contribution of this study on the basis results obtained by the analysis conducted through the three research questions.

SME managers' overall managerial arsenal of HRM. Our study revealed a big gap between normative and ideal descriptions of strategic HRM systems (e.g. Guest 1997) and HRM related thinking of SME managers. In general, the range of HRM practices that managers raised spontaneously on HRM - performance logic was rather narrow compared to detailed lists presented in normative and research oriented HRM papers (e.g. Posthuma et al. 2013), HRM business books (e.g. Ulrich \& Brockbank, 2005) and textbooks (eg. Leopold, 2002). The number of different HRM practices named by a single manager was 10 at most, while, for example, Posthuma et al. (2013) listed 61 different HRM practices (clustered into nine broad categories) used in HRM studies. The managers referred rather self-evident HRM practices such as training, recruitment, and participation of employees, in a flat way, and any other more specific illustrations of HRM practices, such as cross-functional or multiskilled training, multiple tools used to screen applicants, or job enlargement and enrichment (see Posthuma et al. 2013), were mostly missing. For example autonomous job design, internal promotions and performance appraisals, which were "served" to be considered among hotel managers in the survey conducted by Arthur et al. 
(2016), emerged only seldom in the thinking of managers in our sample. SME managers' HRM arsenal, thus, appeared to be rather unsophisticated if compared to its' versatility and potential described in HRM literature. It may be unfair to compare SME managers' thinking to the sophisticated HRM theories presented in the literature, or the knowledge and thinking of HRM specialists. However, the result strengthens the understanding that SME managers cannot be experts in all managerial fields. From SMEs point of view, normative managerial literature offers perhaps too sophisticated view on HRM. Rather, it would be important to develop stage models that gradually enlarge HRM practices as the firm grows. That kind of models would better serve SME managers to adopt HRM thinking relevant enough for their purposes. However, as the above draws an overall picture of the status of SME managers' HRM thinking, the variation between managers was substantial, and it was possible to found real HRM thinkers amongst the managers interviewed. This finding is consistent with the finding of previous studies showing variation both in regard to adoption and intensity of using HRM practices in SMEs (Aragon-Sanchez and Sanchez-Marin 2005; Cassell, Nadin, Gray, and Clegg 2002; Psychogios, Szamosi, Prouska, and Brewster 2015). Our study traces the firm level differences back to differences in managerial thinking. A manager in the CEO position in a SME must be more of a generalist than a specialist, and capable of considering several aspects of the firm simultaneously. The same concerns exist, of course, for CEOs in bigger firms, but the difference is that they usually have a separate HRM function that encourages the use of HRM in a sophisticated manner. SMEs do not possess such resources, which is why managers perform the central HRM role (Arthur et al. 2016). The CEO of an SME must often address several competing issues and this may lead to a situation where HRM issues are not recognized as important and where, therefore, the development of HRM is not among 
the top priorities. This can be harmful for a firm, because it is the people who make the difference in SMEs (Combs et al. 2006).

Patterns of SME managers' causal beliefs. The causal chains between HRM practices, outcomes, and firm performance were most often both short and dispersed. Most of the causal chains managers mentioned specifically had only two elements, as in, flexibility with working times > (promotes) job satisfaction or enlarged job descriptions > (lead to) manpower flexibility. Even those managers who listed several HRM practices or HRM outcomes quite seldom explained how they are linked with each other or improving organizational performance. When mirroring our results with the "HRM bundle-theory" (Guest 2007), even 20 of 37 causal maps of SME managers could be categorized in the skill-enhancing bundle. That was the case in all of the four categories of managerial thinking explaining HRM - performance causality. However, even if the HRM outcome knowledge and skills was the most usual core construct in the cognitive maps, means for developing knowledge and skills were typically explained by only a few HRM practices. The same thing appeared in those nine causal maps, which resembled most motivation-enhancing bundle and in the four maps resembling the empowerment-enhancing bundle. Four of the elicited causal maps did not focus on any of the three bundles clearly. This observation indicates that even if managers see some HRM outcome very important for firm performance the causal linking of the outcome with means and performance goals was quite usually vague. This fact may exhibit the potential synergistic effect of a coherent set of HRM practices and outcomes, which is one of the basic assumptions in the HRM bundle theory (Subramony 2009). 
Different types of managerial thinking on HRM. As pointed out earlier, managers' causal beliefs on HRM differed substantially. Through the analysis procedure developed in this study, the causal beliefs of SME managers were categorized in four groups according to their conceptual richness and cognitive complexity. The resulting typology is a step towards a wider theorizing where managerial thinking can be analyzed against known areas of management. In this study we addressed HRM related managerial issues. The categorization makes it possible to analytically approach managerial thinking. Through the categorization it is possible to get a detailed and comparative picture of each managers' HRM thinking. The value of the two dimensional analysis is based on the separation between conceptual richness and cognitive complexity, which are assumed to be independent of each other. This assumption and the result of empirical analysis make us to propose the appearance of four types of SME managers' HRM thinking:

- Managers with Mature HRM thinking recognize several HRM related issues as means for high organizational performance; characteristic to mature thinking is also manager's ability to link HRM practices and HRM outcomes together and further to various factors of organizational performance; the appearance of one or more HRM related core constructs (usually HRM outcomes) is an important feature of maturity.

- Managers with Narrow HRM thinking recognize a limited number of HRM related issues as means for high organizational performance; however they are able to relatively well link the few HRM issues with each other (practice - outcome link) and further to organizational performance (outcome - performance link).

- Managers with Scattered HRM thinking typically name a lot of HRM related issues; however they do not connect them cohenently with each other with causal logic; this concerns both practice - outcome and outcome - performance links; the absence of HRM core constructs is typical for this type of thinking.

- Managers with Vague HRM thinking can name only few HRM related factors having a connection to organizational performance, which also means the lack of connections between means and outcomes.

Our study develops descriptive theory on SME managers' thinking related to HRM as an organizational performance driver. As a typology based on empirical observations, our findings offer an alternative view to normative and explanatory studies on the role of HRM to firms in 
general and SMEs in particular. In that way our results complement the existing knowledge concerning the role of HRM in SMEs by highlighting the role of the CEO and more precisely his/her causal beliefs on HRM as a performance driver of a firm.

\section{Practical Implications}

SMEs relatively poor HRM can be traced back to managerial preferences, or like in this study, managerial causal beliefs on the connections of HRM and firm performance.

First, HRM should feature in the training of all experts who have the potential to reach managerial positions. This type of education is currently extremely rare in degree programs in technical schools and universities, despite many engineers being likely to have managerial positions during their careers. Second, the topic should feature in the ongoing management training of existing managers. Comprehensive reviews of HRM as a success factor are quite rarely found in the programs of leadership courses. Third, even in those companies where there are HRM professionals, there is a strong argument for training top managers to allow them to become more involved in HRM. This recommendation challenges HRM professionals to take on an educational role with respect to top managers and HRM issues. Without such training, there can be no real possibility of these managers adopting a strategic role.

On more general level, the current study indicates the practice of causal thinking is relatively rare in managerial thinking as a whole. In fact, the interviewees struggled to explain their causal beliefs and several said spontaneously after the interview that this was the first time they had to explain explicitly their thinking on important aspects of business and their causal beliefs about 
performance. Almost all of the interviewed managers assessed the causal mapping procedure to be an interesting and useful exercise that could help them clarify their own thinking on the complex causalities between different factors affecting company performance. We believe that managers would benefit considerably from training requiring them to enunciate causal thinking, either conducted on their own or with some coaching. We do not mean, that managers should try to force the picture of complex and fuzzy business environments as form of simple and linear causalities, but it would be important to consider, what are own beliefs of relations between different actions and outcomes.

\section{Limitations and Suggestions for Future Studies}

The approach of the study unmasks the position of HRM in its purest form and magnitude compared to deductive and thematically predetermined research on HRM. We believe, that by doing this, we have captured some essential features describing the SME managers' HRM thinking and illustrating the variation in their cognitions as potential partial explanations for variety of HRM in SMEs. However, as we approached HRM-related issues within managers' overall thinking on firm performance drivers, the appearance of HRM was always just one part of the complete storyline. We also noticed that in some cases, the managers talked very broadly and vividly about things that were urgent at the moment of the interview. It is possible that some managers interviewed may simply have neglected to mention a few HRM issues that they truly regard as important. Still we believe that given one and a half hours to answer the question "What factors contribute to the firm's success?" they are unlikely to have failed to mention something they really believed in. 
We also call researcher for leaning on and renewing the methodological tools of cognitive research, which flourished a few decades ago and has stayed more in the background recently. Because the business environments are more and more complex and fuzzy, it is even more useful to try understand the patterns and structures in thinking of decision makers in firms.

It is important to bear in mind that our findings cannot be generalized to all SME managers in the mechanical manufacturing industry, not to speak managers in SMEs in general. Also the cultural context obviously manifests in findings of the study. Finland represents Scandinavian welfare society with strong work unions and strong job security of employees in firms, which naturally reflects in our data: some issues may be considered so self-evident that they are not explicitly worded in managers' talk. Therefore we wish other researchers to further investigate managers' thinking of HRM in other countries. In addition, it would be understand that what could be the reasons for variation in knowledge of HR practices and causalities between those and HR outcomes and performance. In our small sample it was not possible to observe the possible influences of education, previous career, examples of other managers etc. in their thinking.

Finally we encourage academics to study the gaps between often idealistic pictures we build ourselves in research and in text book and the reality that manifests in practitioners thinking. Our approach without a predetermined thematic research agenda revealed a very different picture of the position of HRM in top managers' minds compared to that presented in the normative HRM literature. These kind of observations are important when trying to find ways to offer some tools for practitioners to develop their management in reality. 


\section{References}

Allison, C.W. and Hayes, J. (2000). 'Cross-national differences in cognitive style: implications for management'. International Journal of Human Resource Management, 11, 161-70.

Aragon-Sanchez, A., and G. Sanchez-Marin (2005). 'Strategic orientation, management characteristics, and performance: A study of Spanish SMEs'. Journal of Small Business Management, 43(3), 298-08.

Arendt, L. A., R. L. Priem, and H. A. Ndofor (2005). 'A CEO-adviser model of strategic decision making'. Journal of Management, 31(5), 680-699.

Arthur, J.B. (1992). Effects of human resource systems on manufacturing performance and turnover. Academy of Management Journal, 37, 670-687

Arthur, J.B., Herdman, A.O. and Yang, J. (2016). 'How top management HR beliefs and values affect high-performance work system adoption and implementation effectiveness'. Human Resource Management, 55:3, 413-435.

Barr, P. and Huff, A. (1997). 'Seeing isn't believing: understanding diversity in the timing of strategic response'. Journal of Management Studies, 34:3, 337-370.

Bartunek, J. M., Gordon, J. R., and Weathersby, R. P. (1983). 'Developing “complicated”, understanding in administrators'. Academy of Management Review, 8(2), 273-284.

Becker, B. and Gerhart, B. (1996). 'The impact of human resource management on organizational performance: progress and prospect's. Academy of Management Journal, 39:4, 779-800.

Becker, B. and Huselid, M. (2006). 'Strategic human resource management: where do we go from there?' Journal of Management, 32:6, 898-925. 
Boselie, P., Dietz, G. \& Boon, C. (2005). 'Commonalities and contradictions in HRM and performance research'. Human Resource Management Journal, 15:3, 67-94.

Bourne, H. and Jenkins, M. (2005). 'Eliciting Managers' Personal Values: An Adaptation of the Laddering Interview Method'. Organizational Research Methods. 8:4, 410-428.

Budhwar, P.S. and Sparrow, P.R. (2002). 'Strategic HRM through the cultural looking class: Mapping the cognition of British and Indian managers'. Organization Studies, 23:4, 599-638.

Busenbark, J. R., Krause, R., Boivie, S., and Graffin, S. (2016). 'Toward a configurational perspective on the CEO: A review and synthesis of management literature'. Journal of Management, 42(1): 234-268.

Calori, R., Johnson, G. and Sarnin, P. (1994). 'CEO's cognitive maps and the scope of the organization'. Strategic Management Journal, 15, 43-57.

Cardon, M.S and Stevens, C.E. (2004). 'Managing human resources in small organizations: what do we know?' Human Resource Management Review 14 (3), 295-323.

Carlson, D., Upton, N. and Seaman, S. (2006) 'The impact of human resource practices and compensation design on performance: an analysis of family-owned SMEs'. Journal of Small Business Management, 44:4, 531-543.

Cassell, C., Nadin, S., Gray, M. and Clegg, C. (2002). 'Exploring human resource management practices in small and medium sized enterprises'. Personnel Review, 31:6, 671-692.

Cho, T.S. and Hambrick, D.C. (2006). 'Aattention as the mediator between top management team characteristics and strategic change: The case of airline deregulation'. Organization Science 17(4):453-469.

Choo, S.S., Halim, H. and Keng-Howe, I.C. (2010). 'The impact of globalisation on strategic human resources management: the mediating role of managing director in HR'. International Journal of Business Studies,18:1, 101-124. 
Combs, J., Liu, Y., Hall, A. and Ketchen, D. (2006). 'How much do high performance work practices matter? A meta-analysis of their effects on organizational performance'. Personnel Psychology, 59:3, 510-528.

Crilly, D. and Sloan, P. (2012). 'Enterprise logic: Explaining corporate attention to stakeholders from the "inside-out"'. Strategic Management Journal, 33 (10), 1174- 1193.

Daniels, K., Johnson, G. and de Chernatony, L. (1994). 'Differences in Managerial Cognitions of Competition'. British Journal of Management, 5(1), 521-529.

Danks, David (2009). 'The Psychology of Causal Perception and Reasoning'. In Beebee, Hitchcock and Menzies (Eds.). The Oxford Handbook of Causation. Oxford: Oxford University Press, 447-471.

Eden, C. \& Ackermann, F. (1998). 'Analysing and comparing idiographic causal maps'. In Eden and Ackermann. Managerial and organizational cognition: Theory, methods and research, 192209.

Eden, C., Ackermann, F. and Cropper, S. (1992). 'The analysis of cause maps'. Journal of Management Studies, 29 (3), 309-324.

Eggers, K.P. and Kaplan, S. (2009). 'Cognition and renewal: comparing CEO and organizational effects on incumbent adaptation to technical change'. Organization Science, 20(2), 461-477.

Ehrnrooth, M. and Björkman, I. (2012). 'An integrative HRM process theoretization: Beyond signaling effects and mutual gains'. Journal of Management Studies, 49:6, 1109-1135.

Evans, W. R., and Davis, W. D. 2005. 'High-performance work systems and organizational performance: The mediating role of internal social structure'. Journal of Management, 31: 758775.

Guest, D. (1987). 'Human resource roles: creating value, not rhetoric'. Human Resource Planning, 19:3, p. 38-49.

Guest, D. (1997). 'Human resource management and performance: a review and research agenda'. The International Journal of Human Resource Management, 8:3, 263-276.

Guest, D. (1997). 'Human resource management and performance: a review and research agenda'. The International Journal of Human Resource Management, 8(3), 263-276. 
Guest, D. (2011). 'Human resource management and performance: still searching some answers'. Human Resource Management Journal, 21:3, 3-13.

Guthrie, J.P. (2001). 'High-involvement work practices, turnover, and productivity: Evidence from New Zealand'. Academy of Management Journal, 44, 180-190.

Guthrie, J.P. (2001). 'High-involvement work practices, turnover, and productivity: Evidence from New Zealand'. Academy of Management Journal, 44(1), 180-190.

Hodginson, G.P.(1997). 'The cognitive analysis of competitive structures: a review and critique'. Human Relations, 50(6), 625-654.

Hodgkinson, G. P., \& Sparrow, P. R. (2002). The competent organization: A psychological analysis of the strategic management process. Buckingham, UK: Open University Press.Handbook of research strategy and foresight. Cheltenham: Edward Elgar.

Hodgkinson, G. P., and G. Johnson (1994). 'Exploring the mental models of competitive strategists'. Journal of Management Studies, 31(4), 525-551.

Huff, A. S. (1990). 'Mapping strategic thought'. In Huff(Ed.), Mapping Strategic Thought. Chichester: John Wiley, 11-49.

Huff, A.S. (2013). 'Managerial and organizational cognition- Islands of coherence'. In Smith and Hitt (Eds.), Great minds in management- the process of theory development. New York, Oxford University Press, 331-354.

Huselid, M. (1995). 'The impact of human resource management practices on turnover, productivity, and corporate financial performance'. Academy of Management Journal, 38:3, $635-672$.

Ilmarinen, J. \& Ilmarinen, V. (2014). Kehittämistoimilla tuloksia. Hyvä työ-pidempi työura. Teknologiateollisuus. http://www.tyoelama2020.fi/files/586/Hyva_tyo__Pidempi_tyoura_kehittamistoimilla_tuloksia_lyhyt.pdf

Jenkins, M. and Johnson, G. (1997). 'Entrepreneurial intention and outcomes: A comparative causal mapping study'. Journal of Management Studies, 34:6, 0022-2380. 
Jiang, K., Takeuchi, R. \& Lepak, D. (2013). 'Where do we go from here? New perspectives on the black box in strategic human resource management research'. Journal of Management Studies, 50:8, 1448-1480.

Kaplan, S. (2008). 'Cognition, capabilities and incentives: Assessing firm response to the fiveroptic revolution. Academy of Management Journal, 51(4), 672-695.

Kaplan, S. (2011). 'Research in Cognition and Strategy: Reflections on two decades of progress and a look to the future'. Journal of Management Studies, 48(3), 665-695.

Kotey, B. and Slade, P. (2005). 'Formal human resource management practices in small growing firms'. Journal of Small Business Management, 43:1, 16-40.

Laamanen, T. and J. Wallin, (2009). 'Cognitive Dynamics of Capability Development Paths'. Journal of Management Studies, 46(6), 950-981.

Laukkanen, M. (1994) Comparative cause mapping of organizational cognitions. Organizational Science, 5(3), 322-343.

Laukkanen, M. (1998). 'Conducting causal mapping research: opportunities and challenges'. In Managerial and Organizational Cognition. Eds. C Eden and J.C. Spender. Beverly Hills, CA: Sage, 168-191.

Lepak, D. P., Taylor, M. S., Tekleab, A., Marrone, J. A., and Cohen, D. J. (2007). 'An examination of the use of high-investment human resource systems for core and support employees'. Human Resource Management, 46, 223-246.

Lähteenmäki, S., Storey, J. and Vanhala, S. (1998). 'HRM and company performance: the use of measurement and the influence of economic cycles'. Human Resource Management Journal, $8: 2,51-65$.

Leopold, J. (2002). Human resources in organisations. London: Prentice Hall.

Lucas, R.E. and Diener, E. (2003). 'The happy worker. Hyphotheses about the role of positive affect in worker productivity'. In Barrick and Ryan (Eds), Personality and work. Reconsidering the role of personality in organizations. San Francisco: John Wiley \& Sons, Jossey-Bass, 30-59. 
Mäkelä, K. (2017). Työkaari kantaa - teknologiateollisuuden tulevaisuushankkeen väliarviointi. Teknologiateollisuus. http://www.tyoelama2020.fi/files/2394/Tyokaari_kantaa_2017.pdf

Marescaux, E., S. De Winne, and L. Sels (2013). 'HR practices and HRM outcomes: the role of basic need satisfaction'. Personnel Review, 42(1), 4-27.

Markoczy, L. (1995). 'States and belief states'. The International Journal of Human Resource Management, 6, 249-269.

Markoulli, M., Lee, C.I.S.G., Byington, E.and Felps, W.A. (2016). 'Mapping human resource management: reviewing the field and charting future directions'. Human Resource Management Review, 27:3, 367-396.

Marlow, S., Taylor, S. and Thompson, A. (2010).'Informality and formality in medium-sized companies: contestation and synchronization'. British Journal of Management, 21, 954-966.

McNamara, G., Deephouse, D.L., Luce, R.A. (2003). 'Competitive positioning within and across strategic group structure: the performance of core, secondary and solitary firms. Strategic Management Journal, 24:2, 161-81.

Messersmith, J. and Guthrie, J. (2010). 'High performance work systems in emerging organisations: Implications for performance'. Human Resource Management, 49:2, 241-264.

Mitchell, R., Obeidat, S. \& Bray, M, (2013). 'The effect of strategic human resource management on organizational performance: the mediating role of high-performance human resource practices'. Human Resource Management, 52:6, 899-921.

Nadkarni, S., and Barr, P.(2008). 'Environmental context, managerial cognition, and strategic action: an integrated view'. Strategic Management Journal ,29:13, 1395-1427.

Osterman, P. (1994). 'How common is workplace transformation and who adopts it?' Industrial and Labor Relations Review, 47, 173-188.

Pajo, K., Goetzer, A. and Guenole, N. (2010). 'Formal development opportunities and withdrawal behaviors by employees in small and medium-sized enterprises'. Journal of Small Business Management, 48:3, 281-301 
Panda, S. (2011). 'Performance management system: issues and challenges'. Management and Labour Studies, 36:3, 271-280.

Papadakis, V. M. and Barwise, P. (2002). 'How much do CEOs and top managers matter in strategic decision-making?'. British Journal of Management, 13, 83-95.

Pfeffer, J. and Viega, J.F. (1999). 'Putting people first for organizational success'. Academy of Management Executive, 13, 37-48.

Porac, J., H. Thomas, and C. Baden-Fuller (1989). 'Competitive groups as cognitive communities: the case of Scottish knitwear manufacturers'. Journal of Management Studies, 26(4), 397-416.

Porac, J.F., and H.Thomas (1990). ‘Taxonomic mental models in competitor definition'. Academy of Management Review, 15(2), 224-240.

Posthuma, R.A., Campion, M.C., Masimova, M. and Campion, M.A. (2013). 'A high performance work practices taxonomy: Integrating the literature and directing future research'. Journal of Management, 39:5, 1184-1220.

Psychogios, A.G., Szamosi, L.T., Prouska, R. and Brewster, C. (2015). 'A three-fold framework for understanding HRM practices in South-Eastern European SMEs'. Employee Relations, 38:3, $310-331$.

Razouk, A.A. (2011). 'High performance work systems and performance of French small- and medium-sized enterprises: Examining causal order'. International Journal of Human Resource Management, 22:2, 311-330.

Reger, R. \& Huff, A.S. (1993). Strategic groups: A cognitive perspective. Strategic Management Journal, 14(2), 103- 124.

Reger, R. K. and T. B. Palmer (1996). 'Managerial Categorization of Competitors: Using Old Maps to Navigate New Environments'. Organization Science, 7(1), 22-39.

Sadler-Smith, E. (1998). 'Cognitive style: some human resource implications for managers'. International Journal of Human Resource Management, 9, 185-202. 
Sels, L., De Winne,S., Maes, J., Delmotte, J., Faems, D. and Forrier, A. (2006). 'Unravelling the HRM - performance link: value-creating and cost-increasing effects of small business HRM'. Journal of Management Studies, 43:2, 319-342.

Sheehan, M. (2014). 'Human resource management and performance: Evidence from small and medium-sized firms'. International Small Business Journal, 32:5, 545-570.

Snape, E. and Redman, T. (2010). 'HRM practices, organizational citizenship behavior, and performance: A multi-level analysis'. Journal of Management Studies, 47:7, 1219-1247.

Subramony, M. (2009). 'A meta-analytical investigation of the relationship between HRM and firm performance'. Human Resource Management, 48:5, 745-768.

Truss, C., Gratton, L., Hope-Hailey, V., McGovern, P. \& Stiles, P. (1997). 'Soft and hard models of human resource management: a reappraisal'. Journal of Management Studies. 53-73.

Tyler, B.B., and D.R. Gnyawali (2009). 'Managerial Collective Cognitions: An Examination of Similarities and Differences of Cultural Orientations'. Journal of Management Studies, 46(1), 93126.

Ulrich, D. and Brockbank, W. (2005). The HR value proposition. Boston: Harvard Business School Press.

Verreynne, M-L., Parker, P. and Wilson, M. (2013). 'Employment systems in small firms: A multilevel analysis'. International Small Business Journal, 31:4, 405-431.

Walsh, J. P. (1995). 'Managerial and organizational cognition: Notes from a trip down memory lane'. Organization Science, 6(3), 280-321. 


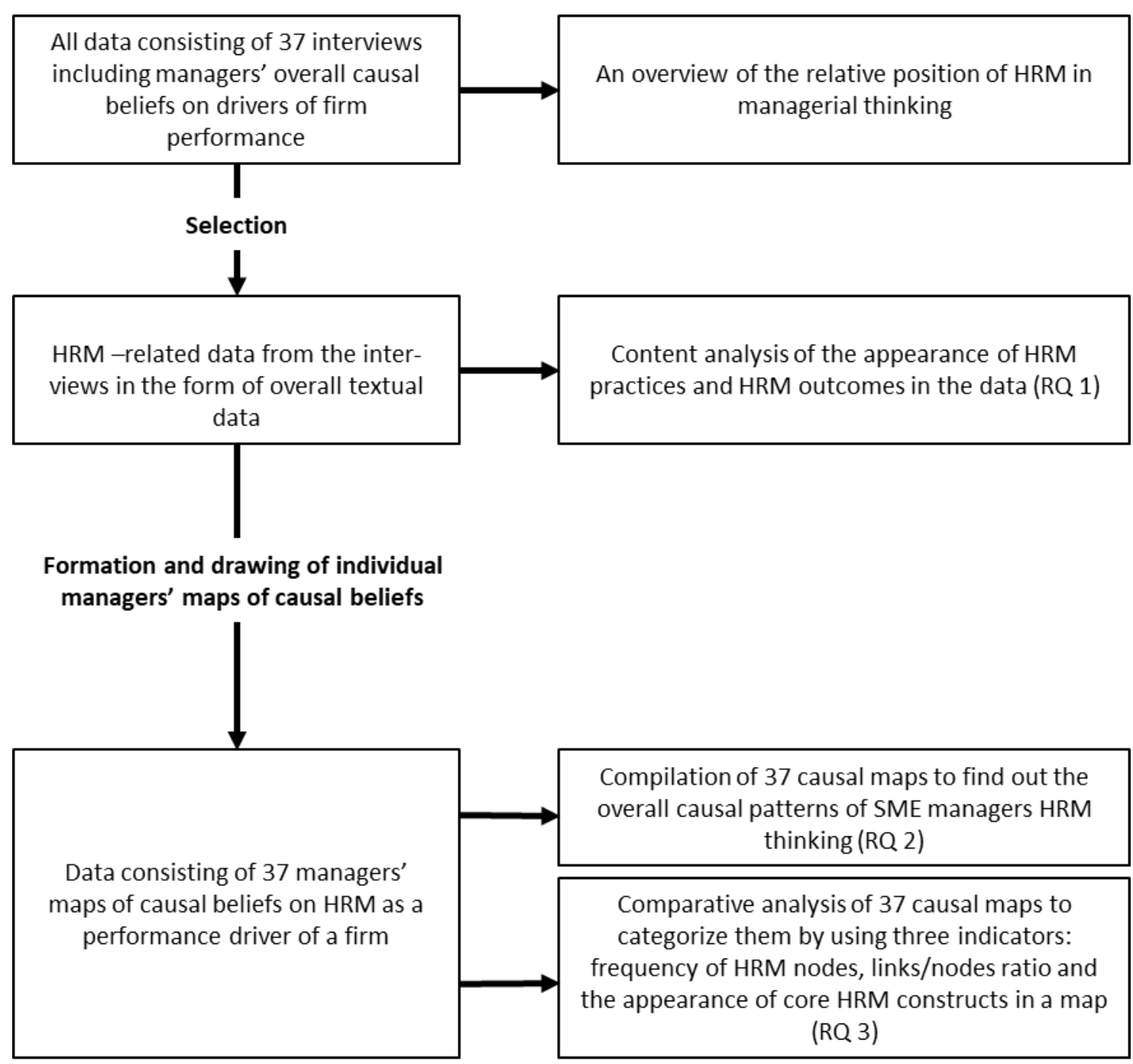

Figure 1. Phases and outputs of empirical analysis 
Figure 2. Examples of typical maps of causal beliefs in four categories found (central core HRM constructs bolded)

Table 1. The appearance of HRM practices in managers' causal beliefs ( $\mathrm{N}=$ number of managers mentioning the issue).

\begin{tabular}{|lc|}
\hline \multicolumn{1}{|c|}{ HRM PRACTICES } & N \\
\hline Training and development & 21 \\
Training (14), Orienteering/induction (1), Work-based learning (7), Developmental discussions & \\
(5), Peer learning (3), Knowledge mapping (2) & 20 \\
Job and work design & \\
Well-specified tasks and work roles (9), Flat organization structure (6), Organizational & \\
development (4), Flexible working times (3), Broad tasks (2) & 13 \\
Employee relations & \\
Participation of employees (13) & 12 \\
Promoting well-being, health, and safety & \\
Occupational safety activities (8), Activities that promote well-being (3), Employee surveys (3), & \\
Occupational health services (32) & 10 \\
Recruitment and selection & 8 \\
Compensation and benefits & 4 \\
Promotions & 4 \\
Resourcing & 2 \\
Performance management and appraisal & 2 \\
\hline
\end{tabular}

Table 2. The appearance of HRM outcomes in managers' causal beliefs ( $\mathrm{N}=$ number of managers mentioning the issue).

\begin{tabular}{|lc|}
\hline \multicolumn{1}{|c|}{ HRM OUTCOMES } & N \\
\hline $\begin{array}{l}\text { Job satisfaction and motivation } \\
\text { Work engagement (14), Job satisfaction (12), Work motivation (10) }\end{array}$ & 28 \\
$\begin{array}{l}\text { Performance of employees } \\
\text { Individual performance in general (9), Development and innovativeness (9), Health (6) } \\
\text { Knowledge and skills }\end{array}$ & 20 \\
\hline
\end{tabular}




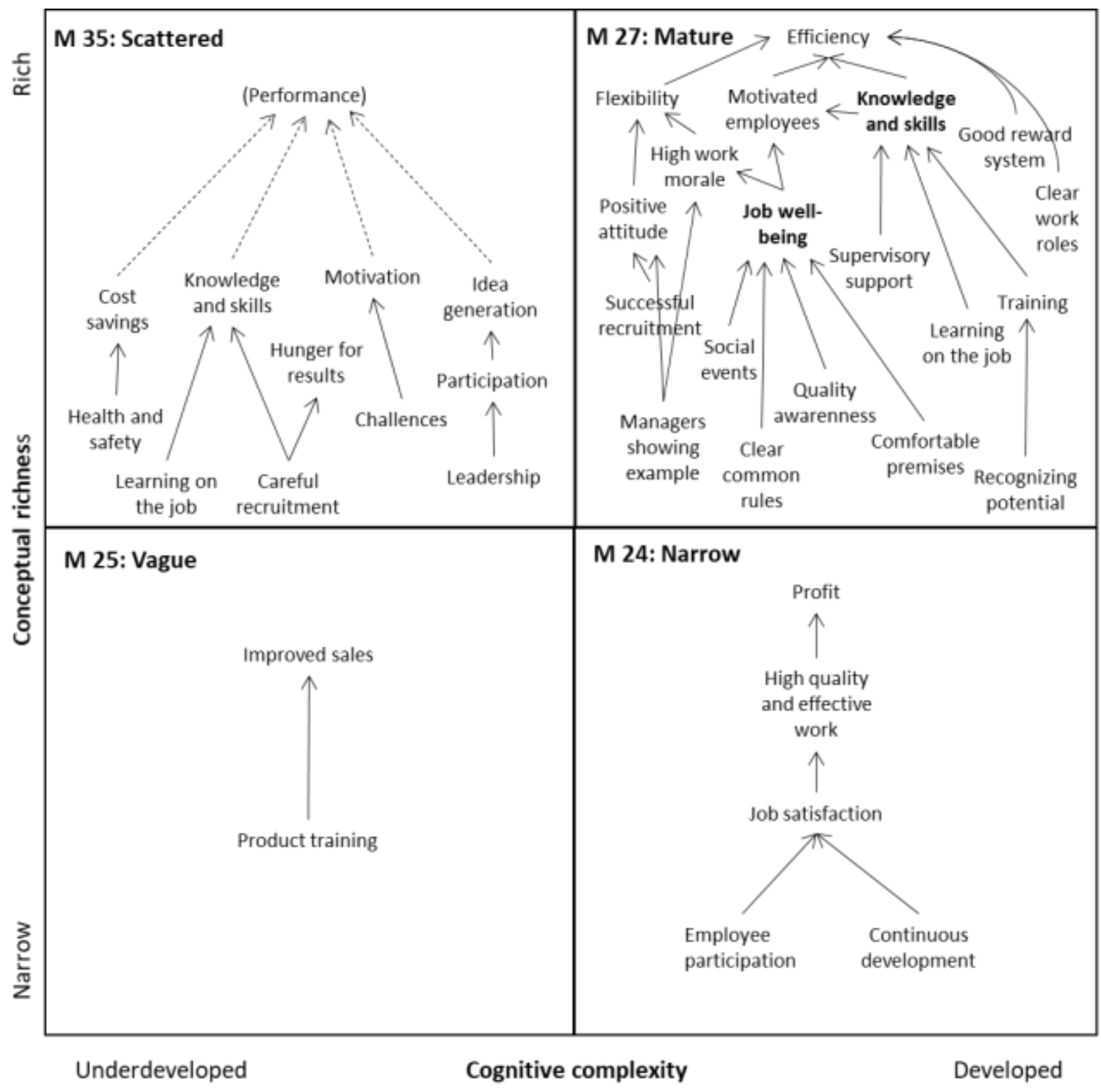

Table 3. Classification of managers on the basis of their causal beliefs of HRM as a performance driver of a firm (core constructs with at least 5 links bolded) 


\begin{tabular}{|c|c|c|c|}
\hline Manager & $\begin{array}{c}\text { All } \\
\text { nodes }\end{array}$ & $\begin{array}{l}\text { Links/nodes } \\
\text { ratio }\end{array}$ & Core HRM constructs \\
\hline \multicolumn{4}{|c|}{ Managers with mature HRM thinking } \\
\hline 1 & + & - & job satisfaction \\
\hline 7 & ++ & + & knowledge and skills \\
\hline 27 & ++ & ++ & work motivation, job well-being, work morale, knowledge and skills \\
\hline 28 & + & ++ & knowledge and skills, work motivation and commitment \\
\hline 29 & + & + & work motivation and commitment \\
\hline 31 & + & + & participation \\
\hline 32 & + & + & knowledge and skills (cost consciousness) \\
\hline 36 & ++ & + & knowledge and skills, organization culture \\
\hline 37 & + & + & innovativeness \\
\hline \multicolumn{4}{|c|}{ Managers with scattered HRM thinking } \\
\hline 3 & + & - & job satisfaction, mutual flexibility \\
\hline 6 & + & + & knowledge and skills \\
\hline 8 & + & + & participation, well-being \\
\hline 15 & + & - & well-being, personnel flexibility \\
\hline 17 & + & + & knowledge and skills \\
\hline 21 & + & - & knowledge and skills (experience -based) \\
\hline 30 & + & - & knowledge and skills, personnel flexibility \\
\hline 35 & ++ & -- & knowledge and skills \\
\hline \multicolumn{4}{|c|}{ Managers with narrow HRM thinking } \\
\hline 2 & - & + & work motivation \\
\hline 5 & - & + & knowledge and skills (technical) \\
\hline 11 & - & + & knowledge and skills (multi-skilled personnel), personnel flexibility \\
\hline 19 & -- & ++ & togetherness \\
\hline 24 & -- & + & job satisfaction \\
\hline 33 & - & - & knowledge and skills \\
\hline 34 & - & ++ & knowledge and skills, job satisfaction \\
\hline \multicolumn{4}{|c|}{ Managers with vague HRM thinking } \\
\hline 4 & -- & - & training and development \\
\hline 9 & - & - & commitment \\
\hline 10 & - & - & personnel flexibility \\
\hline 12 & - & - & knowledge and skills \\
\hline 13 & -- & -- & working towards the vision \\
\hline 14 & - & - & job satisfaction, knowledge and skills \\
\hline 16 & -- & -- & experience \\
\hline 18 & -- & - & experience \\
\hline 20 & -- & -- & attitude \\
\hline 22 & -- & -- & \\
\hline 23 & -- & - & training and development \\
\hline 25 & -- & -- & product training \\
\hline 26 & -- & - & job satisfaction \\
\hline
\end{tabular}

